\title{
The prevalence of quadriceps weakness in COPD and the relationship with disease severity
}

\author{
J.M. Seymour*, ${ }^{\star}$, M.A. Spruit",\$, N.S. Hopkinson`, S.A. Natanek", W.D.C. Man`, \\ A. Jackson , H.R. Gosker ${ }^{+}$, A.M.W.J. Schols ${ }^{+}$, J. Moxham*, \\ M.I. Polkey ${ }^{\uparrow, f}$ and E.F.M. Wouters ${ }^{\#,+, f}$
}

ABSTRACT: Quadriceps strength relates to exercise capacity and prognosis in chronic obstructive pulmonary disease (COPD). We wanted to quantify the prevalence of quadriceps weakness in COPD and hypothesised that it would not be restricted to patients with severe airflow obstruction or dyspnoea.

Predicted quadriceps strength was calculated using a regression equation (incorporating age, sex, height and fat-free mass), based on measurements from 212 healthy subjects. The prevalence of weakness (defined as observed values 1.645 standardised residuals below predicted) was related to Global Initiative for Chronic Obstructive Lung Disease (GOLD) stage and Medical Research Council (MRC) dyspnoea score in two cohorts of stable COPD outpatients recruited from the UK $(n=240)$ and the Netherlands $(n=351)$.

$32 \%$ and $33 \%$ of UK and Dutch COPD patients had quadriceps weakness. A significant proportion of patients in GOLD stages 1 and 2, or with an MRC dyspnoea score of 1 or 2, had quadriceps weakness ( 28 and $26 \%$, respectively). These values rose to $38 \%$ in GOLD stage 4 , and $43 \%$ in patients with an MRC Score of 4 or 5.

Quadriceps weakness was demonstrable in one-third of COPD patients attending hospital respiratory outpatient services. Quadriceps weakness exists in the absence of severe airflow obstruction or breathlessness.

\section{KEYWORDS: Chronic obstructive pulmonary disease, muscle strength}

$\mathbf{P}$ atients with chronic obstructive pulmonary disease (COPD) may exhibit cachexia or skeletal muscle dysfunction [1]. Reduced quadriceps strength contributes to poor exercise performance [2] and has been linked to increased healthcare utilisation [3] and mortality [4]. Whilst the pathophysiology of skeletal muscle dysfunction and wasting is multi-factorial, inactivity is likely to play a key role. Reduced muscle strength is more readily demonstrable in the lower limbs $[5,6]$ of COPD patients and a "downward disease spiral" has been hypothesised, in which advancing dyspnoea leads to a sedentary lifestyle and de-conditioning of the locomotor muscles, and thus further inactivity [7]. Reduced exercise capacity has been related to increased dyspnoea measured by the Medical Research Council (MRC) dyspnoea scale [8] in the presence of preserved whole body fat-free mass (FFM) indices [9]. Improved quadriceps muscle strength and endurance are thought to underlie much of the increased exercise capacity observed following multidisciplinary pulmonary rehabilitation for COPD [10]. Access to such programmes remains challenging [11]; international guidelines recommend pulmonary rehabilitation for patients only with a MRC dyspnoea score of $\geqslant 3$ [12].

Isometric quadriceps maximum voluntary contraction strength (QMVC) is commonly used to quantify quadriceps strength and is typically reduced in moderate-to-severe COPD patients by $\sim 30 \%$ when compared with age- and gendermatched healthy subjects [5, 13]. However, quadriceps strength varies widely in such healthy subjects; in the classic description of QMVC measurement, strength was normalised to body weight [14]. Predictive equations have been applied to COPD cohorts, but these were derived from a small number of healthy subjects [15]. This study aimed to identify the lower limit of normal quadriceps strength adjusting for anthropometric factors across an age range comparable to that typically observed in COPD, and estimate the
AFFILIATIONS

*Dept of Respiratory Medicine, King's College London School of Medicine, and

'Royal Brompton Hospital, London, UK.

\#Dept of Development \& Training, Ciro, Centre of Expertise for Chronic Organ Failure, Horn, and +Dept of Respiratory Medicine, Maastricht University Medical Center+ (MUMC+), Maastricht, The Netherlands.

${ }^{\S}$ These authors contributed equally to this study.

${ }^{f}$ Joint senior authors.

CORRESPONDENCE

J.M. Seymour

Dept of Respiratory Medicine

King's College Hospital

London

SE5 9RJ

UK.

E-mail: john.seymour@kcl.ac.uk

Received:

July 052009

Accepted after revision:

Oct 192009

First published online:

Nov 062009

European Respiratory Journal

Print ISSN 0903-1936

Online ISSN 1399-3003 
prevalence of quadriceps weakness in two independent patient cohorts. We wished to quantify the prevalence of quadriceps weakness in COPD, and hypothesised that it would not be restricted to patients with severe airflow obstruction, dyspnoea or FFM loss.

\section{METHODS}

\section{Patients and study design}

Isometric QMVC was measured in 212 healthy volunteers (aged 40-90 yrs) who had participated in research studies at the Muscle Laboratories at King's College Hospital and Royal Brompton Hospital (London, UK), between October 2002 and July 2008. Raw data from some subjects have contributed to previous work $[5,16,17]$. Subjects were recruited by advertisement or from a register of healthy elderly volunteers maintained on the King's Hospital campus by the Department of Elderly Medicine. Although healthy volunteers had a forced expiratory volume in $1 \mathrm{~s}(\mathrm{FEV} 1)>80 \%$ predicted and an FEV1/ forced vital capacity (FVC) ratio $>70 \%$, they included both never and ex-smokers. All reported no respiratory symptoms and no co-morbidity affecting the legs. QMVC measurements were related to anthropometric variables of age, gender, height and FFM, and a regression equation derived to predict QMVC.

Two COPD cohorts were analysed retrospectively; predicted QMVC strength was calculated from the healthy regression equation. As with controls, raw data from some patients have previously been reported [5, 16-18]. The first COPD cohort of 240 subjects comprised stable community dwelling patients who had accessed hospital outpatient services and participated in physiological research at the aforementioned UK centres. The second COPD cohort comprised 351 patients attending their first clinical assessment at a Dutch rehabilitation hospital (Ciro, Center of Expertise for Chronic Organ Failure, Horn, the Netherlands) between December 2005 and October 2007, following referral from their treating respiratory physician. British healthy volunteers and patients included all those in whom both QMVC and a complete set of anthropometric variables had been measured. Dutch patients were identified from patients in whom non-volitional assessment of quadriceps strength had additionally been performed. All centres had local ethical committee approval and participants gave written informed consent.

The prevalence of quadriceps weakness was calculated in the British and Dutch COPD cohorts according to Global Initiative for Chronic Obstructive Lung Disease (GOLD) stage [19]. The role of exertional dyspnoea in the aetiology of quadriceps weakness and the relationship with other prognostic variables was explored using additional data (MRC dyspnoea score [8] and BODE (body mass index (BMI), airflow obstruction, dyspnoea, exercise capacity) index [20]) available for the Dutch COPD cohort.

\section{Measurements}

Both clinical centres participated in the 2003-2006 ENIGMA project (QLK6-CT-2002-02285) to investigate muscle function in COPD $[18,21]$, and measured supine isometric QMVC with the knee joint at $90^{\circ}$, using apparatus described by EDWARDS et al. [14]; measurement techniques were standardised by reciprocal visits at the start of the project. QMVC was the highest mean force that could be sustained over $1 \mathrm{~s}$. We accepted the greatest of at least three reproducible efforts and care was taken to immobilise the hip joint. FFM was estimated using $50 \mathrm{~Hz}$ electrical bioimpedance (Bodystat $₫$ 1500; Bodystat $₫$, Douglas, Isle of Man) [22] in the nonfasted state. Spirometry and pulmonary function tests (diffusing capacity for carbon monoxide $(D \mathrm{~L}, \mathrm{CO})$, lung volume estimation by body plethysmography and arterial blood gas analysis) were performed according to European Respiratory Society (ERS)/American Thoracic Society (ATS) recommendations [23-25]. Additional measurements in the Dutch cohort included whole-body and regional (lower-limb) lean mass by dual energy x-ray absorbtiometry (DEXABODY and DEXALEG, respectively) [26]. Nonvolitional strength assessment used supramaximal magnetic femoral nerve stimulation to generate the quadriceps twitch response (TwQ) [27]. Unpotentiated quadriceps twitches were obtained using a $70 \mathrm{~mm}$ figure of eight coil (Magstim Co. Ltd, Whitland, UK), following 20-min of rest on the same apparatus as that described for the QMVC; the mean of a minimum of five reproducible twitches was used for analysis. The 6-min walk distance (6MWD) was measured according to published guidelines after a practice walk [28]. Peak cycle work (Wpeak) was measured by symptom-limited cycle ergometery. $1 \mathrm{~min}$ of unloaded cycling was followed by $10 \mathrm{~W} \cdot \mathrm{min}^{-1}$ increments. Patients cycled at 60 revolutions $\cdot \mathrm{min}^{-1}$ until exhaustion [29]. Health-related quality of life was measured by the St George's Respiratory Questionnaire (SGRQ) [30].

\section{Statistical analysis}

Analyses were performed using SPSS $_{\circledR}$ Version 16.0 (SPSS Inc., Chicago, IL, USA) or GraphPad Prism ${ }_{\circledR}$ Version 5.0 (GraphPad Software Inc., San Diego, CA, USA). Between-group comparisons used ANOVA, with post hoc analysis (Bonferonni) for more than two groups. Correlations were described using Pearson coefficients to two decimal places. Multiple linear regression, using a single entry step of anthropometric covariables correlated with QMVC strength, analysed the dependence of QMVC in healthy subjects on height, FFM, age and sex. Weakness was defined in patients as a QMVC $<1.645$ standardised residuals from the healthy predicted value. FEV1 \% pred was added as a co-variable in a similar analysis of all COPD patients. The prevalence of QMVC weakness between COPD cohorts and sex was compared by the Chi-squared test; logistic regression was used to assess the likelihood of quadriceps weakness being present according to co-variables of disease severity (FEV1 or GOLD Stage) and/or dyspnoea (MRC Dyspnoea Scale). GOLD or MRC classes were combined with the next level of severity if $<50$ patients were counted. Statistical significance was accepted for $p$-values $<0.05$. Additional comparisons were made between patients with weak and normal quadriceps strength in the Dutch cohort. The effect of weakness on 6MWD and Wpeak was analysed using multiple linear regression, adjusting for anthropometric and pulmonary function co-variables that differed significantly between these groups. Volitional and nonvolitional quadriceps strength normalised for leg muscle mass were also compared.

\section{RESULTS}

\section{Quadriceps strength in healthy subjects}

Participant characteristics are shown in table 1. In healthy subjects, QMVC was greater in males $(13.3 \mathrm{~kg}, 95 \%$ CI $10.5-16.1 \mathrm{~kg}$; 
$\mathrm{p}<0.001)$ and correlated with age $(\mathrm{r}=0.29 ; \mathrm{p}<0.001)$, height $(0.56 ; \mathrm{p}<0.001)$ and FFM $(0.68 ; \mathrm{p}<0.001)$. The regression equation describing predicted QMVC force $\left(\mathrm{r}^{2}=0.51\right)$ in $\mathrm{kg}$ was:

\section{$56.2-(0.30 \times$ age in yrs $)+(0.68 \times$ FFM in $\mathrm{kg})-$ \\ $(0.15 \times$ height in $\mathrm{cm})-(3.42$ if female $)$}

Multiple linear regression analysis identified age and FFM as statistically independent factors (table 2). All covariables had a calculated tolerance $>0.1$, suggesting that none was redundant in the aformentioned equation. The residual standard deviation from the analysis was $8.58 \mathrm{~kg}$; therefore, patients with an ((observed-predicted QMVC)/8.58) <-1.645, were considered weak. $8 \%$ of healthy subjects had weak quadriceps based on this cut-off. Predicted QMVC was similar in the COPD groups (UK 74.8 $\pm 20.5 \%$, the Netherlands $72.2 \pm 18.2 \%$; $p=0.353$ ). Allowing for the dependence of quadriceps strength on the anthropometric variables reported in healthy subjects, each percentage point loss of FEV1 in COPD was associated with a reduction in QMVC of only $47 \mathrm{~g}$ (95\% CI -13- $-82 \mathrm{~g}$; $\mathrm{p}=0.007$; table 2).

\section{Quadriceps strength and GOLD stage}

The overall prevalence of quadriceps weakness was 32\%, and was statistically similar in males and females, and between COPD cohorts (table 3). The prevalence of weakness in COPD according to GOLD stage is illustrated in figure $1.28 \%$ of British patients and $34 \%$ of Dutch patients in the combined GOLD stage $1 / 2$ category demonstrated quadriceps weakness. Unsurprisingly, the highest prevalence of weakness was observed in those with the most severe airflow obstruction (38\% in GOLD stage 4$)$; however, there was no significant difference in prevalence between GOLD categories shown in figure 1.

This study did not include GOLD stage 0 subjects; however, $107(50 \%)$ healthy subjects had smoking histories $>1$ pack-yr. Healthy subjects were re-analysed post hoc, adding prior or current smoking status as a group variable. In addition to the dependence of QMVC on the variables previously described, a smoking history was independently associated with a lower QMVC (-3.4 kg, 95\% CI -5.7- -1.0 kg; p=0.005). There was no correlation between QMVC and self-reported pack years; current smoking status did not affect the QMVC in COPD patients.

\section{Quadriceps weakness in COPD and the relationship with a low FFM index}

Sex-specific cut-offs to describe a low FFM index in COPD have been proposed [31, 32]. Despite the relationship between QMVC and FFM described in table 3, neither the proposed lower limit of normal FFM index (10th percentile) previously reported from a large well-described Danish cohort [31] nor that observed among healthy subjects in this study, was predictive of quadriceps weakness in COPD.

\section{Quadriceps strength in relation to dyspnoea and BODE score in Dutch patients}

$26 \%$ of Dutch patients with mild breathlessness (MRC Dyspnoea Scores 1 or 2) demonstrated quadriceps weakness (fig. 2). The highest prevalence of weakness was observed in subjects with the most severe dyspnoea (MRC dyspnoea score 4 or 5). The odds ratio for quadriceps weakness among MRC dyspnoea scores of 4 or 5 compared with scores of 1,2 or 3, was

TABLE 1 Baseline characteristics of the three cohorts studied

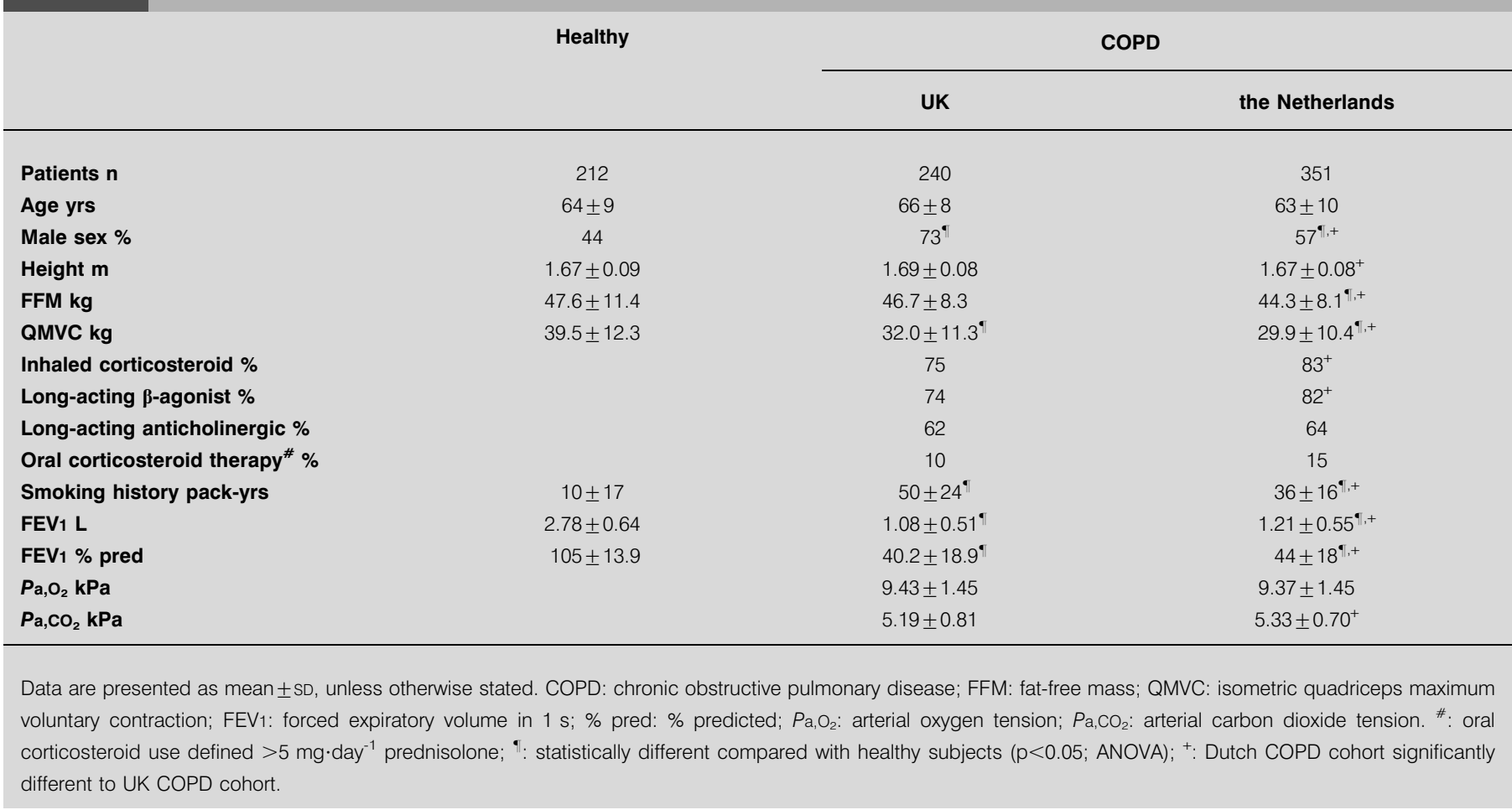


TABLE 2 Dependence of quadriceps maximum voluntary contraction strength (QMVC) on anthropometric factors in chronic obstructive pulmonary disease (COPD)

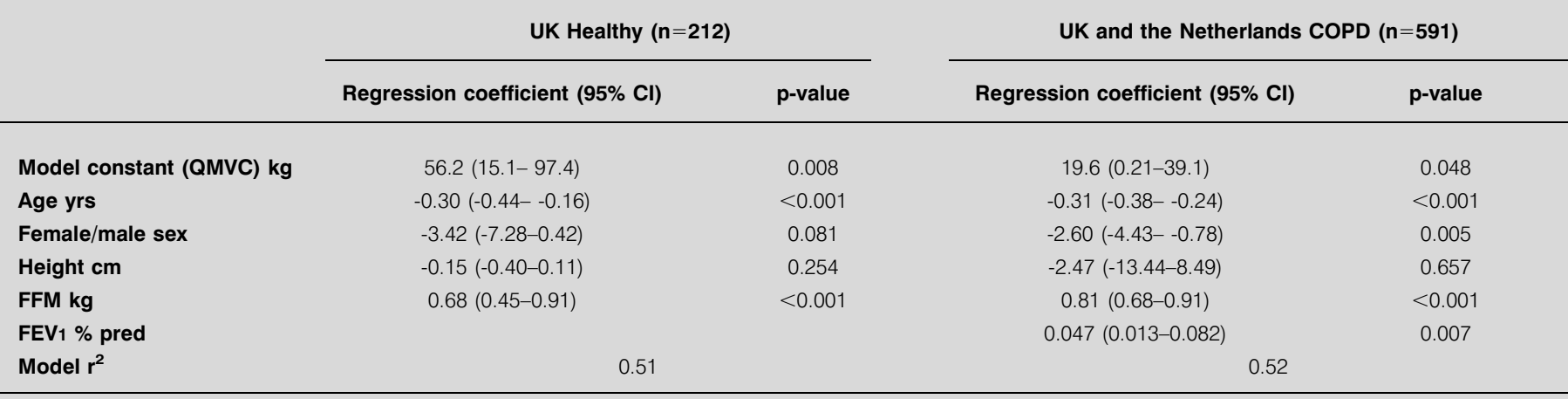

Results of multiple linear regression analyses of healthy and COPD patients are shown. Regression coefficients indicate the change in QMVC force per unit change of each covariable indicated. Sex difference represents females compared with males. $p$-values $<0.05$ suggest a statistically independent determinant in the regression equation. Sex did not reach the predetermined level of significance when COPD cohorts were analysed separately. FFM: fat-free mass; FEV1: forced expiratory volume in 1 s; \% pred; \% predicted.

2.46 (95\% CI 1.54-3.94; $\mathrm{p}<0.001)$. When adjusted for the severity of airflow obstruction, the presence of severe dyspnoea (MRC scores 4 or 5) remained an independent predictor of quadriceps weakness in the Dutch cohort (OR 2.21, 95\% CI 1.32-3.71; $\mathrm{p}=0.003)$. The prevalence of quadriceps weakness in the Dutch cohort divided according to the BODE quartiles previously reported by CELLI et al. [20], is illustrated in figure 3. Quadriceps weakness was present in one-fifth of patients in the BODE quartile associated with the best prognosis (a BODE score of $0-2$ ).

\section{Relationship between weakness and exercise performance in Dutch patients}

Table 4 compares Dutch COPD patients, with and without quadriceps weakness. FFM index was similar in both groups. Patients with quadriceps weakness had worse airflow obstruction

TABLE 3 Prevalence of quadriceps weakness in chronic obstructive pulmonary disease (COPD)

\begin{tabular}{|c|c|c|c|c|}
\hline & \multirow[t]{2}{*}{ UK Healthy } & \multicolumn{3}{|c|}{ COPD } \\
\hline & & UK & the Netherlands & UK and the Netherlands \\
\hline \multicolumn{5}{|l|}{ Male } \\
\hline Subjects $n$ & 94 & 161 & 200 & 361 \\
\hline BMl $\mathrm{kg} \cdot \mathrm{m}^{-2}$ & $26.1 \pm 3.3$ & $24.4 \pm 4.8^{\#}$ & $24.2 \pm 4.5^{\#}$ & $24.6 \pm 4.4^{\#}$ \\
\hline COPD patients with weak QMVC $n$ (\%) & & $45(28)$ & $68(34)$ & $113(31)^{\#}$ \\
\hline \multicolumn{5}{|l|}{ Female } \\
\hline Subjects $n$ & 118 & 79 & 151 & 230 \\
\hline BMl $\mathrm{kg} \cdot \mathrm{m}^{-2}$ & $24.1 \pm 4.2^{\bullet}$ & $24.4 \pm 5.0$ & $23.2 \pm 4.2$ & $23.6 \pm 4.6^{\#}$ \\
\hline FFM index $\mathrm{kg} \cdot \mathrm{m}^{-2}$ & $15.2 \pm 1.2^{\bullet}$ & $15.4 \pm 1.9^{\circ}$ & $14.6 \pm 1.5^{\#, 9,+}$ & $14.9 \pm 1.9^{\#, \cdot}$ \\
\hline QMVC kg & $33.6 \pm 8.4^{\bullet}$ & $25.7 \pm 9.9^{\#, \bullet}$ & $24.6 \pm 6.9^{\# \cdot 9}$ & $24.9 \pm 8.1^{\#, 9}$ \\
\hline BMl $\mathrm{kg} \cdot \mathrm{m}^{-2}$ & $24.9 \pm 3.9$ & $24.4 \pm 4.8$ & $23.8 \pm 4.4^{\#}$ & $24.0 \pm 4.6^{\#}$ \\
\hline FFM index $\mathrm{kg} \cdot \mathrm{m}^{-2}$ & $16.8 \pm 2.6$ & $16.2 \pm 2.2^{\#}$ & $15.7 \pm 2.1^{\#,+}$ & $15.9 \pm 2.1^{\#}$ \\
\hline QMVC kg & $39.5 \pm 12.3$ & $32.0 \pm 11.3^{\#}$ & $29.9 \pm 10.4^{\#,+}$ & $30.7 \pm 10.8^{\#}$ \\
\hline COPD patients with weak QMVC $n(\%)$ & & $76(32)$ & $115(33)$ & $191(32)$ \\
\hline
\end{tabular}

Data are presented as mean $\pm \mathrm{SD}$, unless otherwise stated, for patients diagnosed with quadriceps weakness, split by sex and disease cohort. Body mass index (BMI), fat-free mass (FFM) index and quadriceps maximum voluntary contraction strength (QMVC) in each group are shown for reference. ${ }^{\#:} \mathrm{p}<0.05$ compared with healthy subjects; ${ }^{\top}$ : $p<0.05$ between males and females; ${ }^{+}$: $p<0.05$ between UK and Dutch COPD patients. 


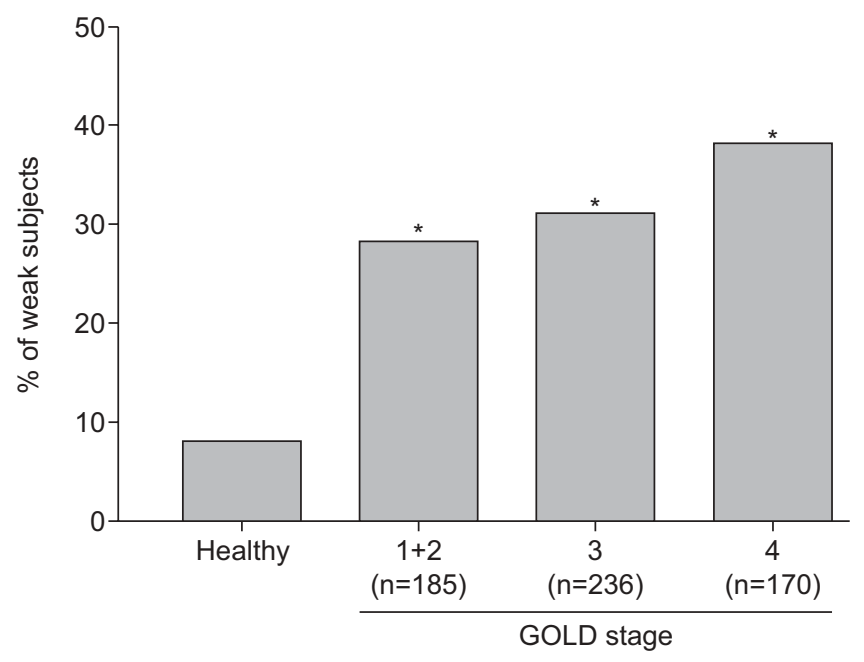

FIGURE 1. Prevalence of quadriceps weakness in chronic obstructive pulmonary disease by Global Initiative for Chronic Obstructive Lung Disease (GOLD) stage. GOLD 1 and 2 are combined given GOLD 1 had $<50$ subjects. 8\% of healthy subjects had a quadriceps maximum voluntary contraction strength $<1.645$ standard residuals below their predicted value; the prevalence of weakness was greater $\left(p<0.05 ;{ }^{*}\right)$ in all GOLD stages than in healthy subjects. There was no significant difference in the prevalence of weakness between GOLD stages.

(lower FEV1), reduced gas transfer coefficient $(D \mathrm{~L}, \mathrm{CO})$, reduced exercise capacity (as judged by the 6MWD) and impaired health-related quality of life (as determined by the SGRQ). Multiple linear regression analysis suggested that quadriceps weakness was associated with a reduction in $6 \mathrm{MWD}$ of $30 \mathrm{~m}(95 \% \mathrm{CI} 8-53 \mathrm{~m}$; $\mathrm{p}=0.008)$, or Wpeak of $6 \mathrm{~W}$ (95\% CI $0.1-10 \mathrm{~W} ; \mathrm{p}=0.047)$, independent of the anthropomorphic variables related to these tests, FEV1 or DL,CO.

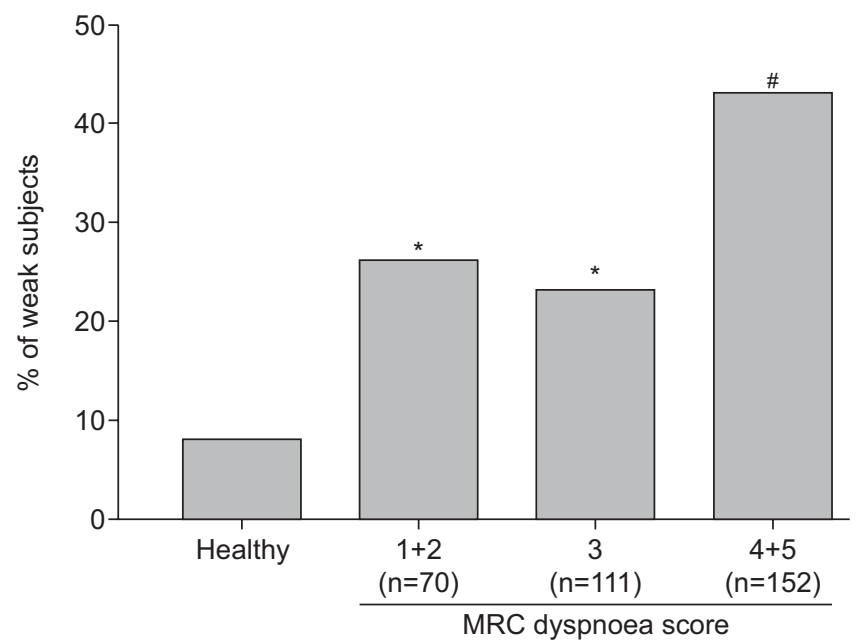

FIGURE 2. Prevalence of quadriceps weakness by Medical Research Council (MRC) dyspnoea scale score in Dutch chronic obstructive pulmonary disease (COPD) patients. MRC score 1 and 2, and 4 and 5 were combined, given observed counts of $<50$ in groups 1 and $5.8 \%$ of healthy subjects had a quadriceps maximum voluntary contraction strength $<1.645$ standard residuals below their predicted value; the prevalence of weakness was significantly greater in COPD $\left(p<0.05 ;{ }^{*}\right)$ for all MRC dyspnoea scores. The prevalence of weakness in MRC $4+5$ was significantly greater than in MRC $1+2$ or $3\left(p<0.05 ;{ }^{*}\right)$.
A diagnosis of quadriceps weakness was unsurprisingly associated with reduced lower-limb lean mass (DEXALEG), but also reduced QMVC (fig. 4) and TwQ per unit DEXALEG.

\section{DISCUSSION}

Using predicted values generated from a cohort of middle-aged and older individuals without spirometric evidence of airflow obstruction, quadriceps weakness was observed in approximately one-third of COPD patients accessing hospital outpatient services, in two European countries. Quadriceps weakness was demonstrated in approximately one-quarter of patients with only mild airflow obstruction (defined by the British Thoracic Society as FEV1 >50\% [12], equivalent to GOLD stage 1 or 2) or mild dyspnoea (MRC dyspnoea score of 1 or 2).

\section{Critique of the method}

The study was retrospective in design and the regression analyses derived using the healthy data would ideally be verified in a prospective cohort. Although participating centres employed common measurement protocols, they did not use extreme measures (e.g. transport of patients between centres as biological controls) to absolutely exclude measurement differences arising from technique or equipment. However, a similar prevalence of weakness was found in two large COPD cohorts from two countries, despite differences in age and sex distribution, suggesting that differences arising from measurement technique were small. Both age and sex were considered when predicting quadriceps strength in patients, and may contribute to the observed similarity.

Clearly additional factors exist that might determine quadriceps strength. For example, the age range of the healthy subjects was selected to be similar to that typically observed among patients presenting with COPD; however, the majority of females were likely to be post-menopausal. Whether the same predictive estimates extend to pre-menopausal females or younger males is unclear. Another obvious limitation of a

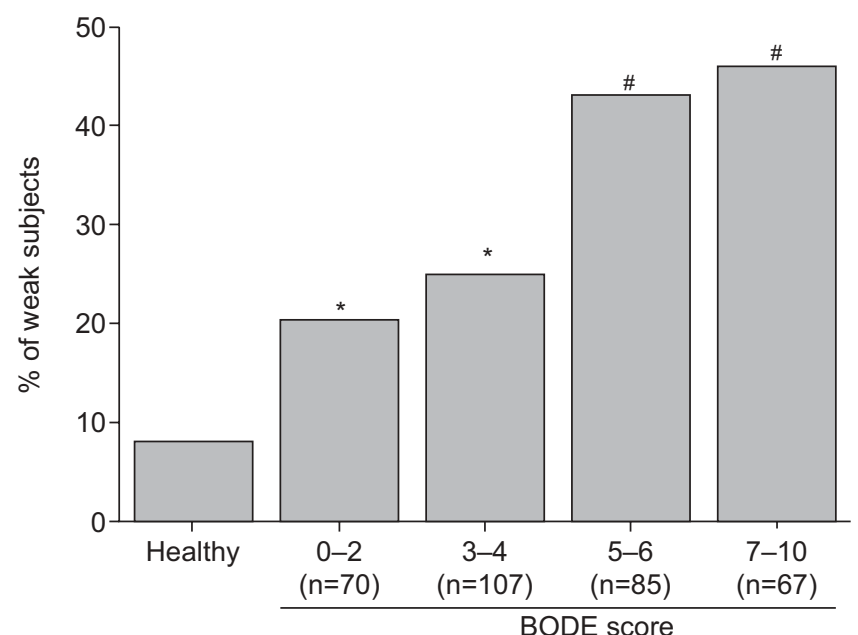

FIGURE 3. Prevalence of quadriceps weakness according to BODE (body mass index, airflow obstruction, dyspnoea, exercise capacity) score [20] in Dutch chronic obstructive pulmonary disease patients. The prevalence of weakness was significantly greater $\left(\mathrm{p}<0.05 ;{ }^{*}\right)$ in all BODE groupings than in healthy subjects; the prevalence of weakness in BODE groupings $5-6$ or $7-10$ was significantly greater than in $0-2$ and $3-4\left(p<0.05 ;{ }^{*}\right)$. 


\begin{tabular}{|c|c|c|c|c|}
\hline \multirow[t]{2}{*}{ TABLE 4} & \multicolumn{4}{|c|}{$\begin{array}{l}\text { Clinical characteristics of Dutch chronic } \\
\text { obstructive pulmonary disease patients with and } \\
\text { without quadriceps weakness }\end{array}$} \\
\hline & & Normal QMVC & Weak QMVC & p-value \\
\hline \multicolumn{2}{|l|}{ Subjects $n$} & 236 & 115 & \\
\hline \multicolumn{2}{|l|}{ Age yrs } & $63 \pm 9$ & $63 \pm 11$ & 0.487 \\
\hline \multicolumn{2}{|l|}{ Male sex \% } & 56 & 59 & $0.647^{\#}$ \\
\hline \multicolumn{2}{|c|}{$\mathrm{FFM}$ index $\mathrm{kg} \cdot \mathrm{m}^{-2}$} & $15.7 \pm 2.1$ & $15.8 \pm 2.1$ & 0.583 \\
\hline \multicolumn{2}{|c|}{ DEXAвODY lean mass $\mathrm{kg}$} & $45.6 \pm 9.2$ & $43.6 \pm 8.7$ & 0.057 \\
\hline \multicolumn{2}{|c|}{ DEXALEG lean mass kg } & $14.1 \pm 3.2$ & $13.2 \pm 3.0$ & 0.013 \\
\hline \multicolumn{2}{|c|}{ QMVC/DEXALEG } & $2.38 \pm 0.43$ & $1.71 \pm 0.32$ & $<0.001$ \\
\hline \multicolumn{2}{|c|}{ TwQ/DEXALEG } & $0.56 \pm 0.16$ & $0.46 \pm 0.14$ & $<0.001$ \\
\hline \multicolumn{2}{|c|}{ FEV $_{1} \%$ pred } & $46.2 \pm 18.2$ & $40.6 \pm 17.0$ & 0.006 \\
\hline \multicolumn{2}{|c|}{$D \mathrm{~L}, \mathrm{CO} \%$ pred } & $59.7 \pm 11.2$ & $56.3 \pm 10.8$ & 0.008 \\
\hline \multicolumn{2}{|l|}{ RV/TLC \% } & $46.9 \pm 16.6$ & $51.3 \pm 17.8$ & 0.070 \\
\hline \multicolumn{2}{|l|}{$\mathrm{Pa}, \mathrm{O}_{2} \mathrm{kPa}$} & $9.40 \pm 1.36$ & $9.21 \pm 1.48$ & 0.237 \\
\hline \multicolumn{2}{|l|}{$\mathrm{Pa}, \mathrm{CO}_{2} \mathrm{kPa}$} & $5.29 \pm 0.66$ & $5.39 \pm 0.76$ & 0.192 \\
\hline \multicolumn{2}{|l|}{ 6MWD m } & $452 \pm 119$ & $403 \pm 108$ & $<0.001$ \\
\hline \multicolumn{2}{|l|}{ Wpeak W } & $74 \pm 33$ & $62 \pm 29$ & 0.002 \\
\hline \multicolumn{5}{|l|}{ SGRQ Score } \\
\hline \multicolumn{2}{|l|}{ Total score } & $52.8 \pm 17.0$ & $57.6 \pm 16.0$ & 0.018 \\
\hline \multicolumn{2}{|l|}{ Symptoms } & $60.2 \pm 20.3$ & $65.5 \pm 19.5$ & 0.033 \\
\hline \multicolumn{2}{|l|}{ Activities } & $68.3 \pm 19.4$ & $74.1 \pm 18.1$ & 0.012 \\
\hline \multicolumn{2}{|l|}{ Impacts } & $41.7 \pm 18.9$ & $45.8 \pm 18.7$ & 0.076 \\
\hline
\end{tabular}

Data are presented as mean $\pm \mathrm{SD}$, unless otherwise stated. QMVC: isometric quadriceps maximum voluntary contraction; FFM: fat-free mass; DEXABODY and DEXALEG, dual energy $x$-ray absorptiometry measurement of whole body and lower limb, respectively; TwQ: twitch quadriceps force following magnetic femoral nerve stimulation; FEV1: forced expiratory volume in $1 \mathrm{~s} ; \%$ pred: \% predicted; $D \mathrm{~L}, \mathrm{CO}$ : diffusing capacity for carbon monoxide; $\mathrm{RV}$ : residual volume; TLC: total lung capacity; $\mathrm{Pa}, \mathrm{O}_{2}$ : arterial oxygen tension; $\mathrm{Pa}_{\mathrm{a}} \mathrm{CO}_{2}$ : arterial carbon dioxide tension; 6MWD, 6-min walk test distance; Wpeak: peak exercise capacity measured by incremental cycle ergometry; SGRQ: St George's Respiratory Questionnaire (lower score denotes improvement). p-values were derived from ANOVA unless indicated and significant values are shown in bold. \#: Fishers exact test was used.

retrospective study is that of the data available. Objective measurements of activity levels (e.g. using accelerometry) are relevant to lower limb strength but were unknown. Cardiovascular comorbidity is common in COPD, and the absence of left ventricular dysfunction or occult peripheral vascular disease was not definitively excluded in all patients. This could be more relevant to the Dutch clinical population than the British research participants, in whom clinically overt disease was excluded. Recruitment bias toward patients with weakness or low activity levels should be recognised, particularly among patients referred to a rehabilitation hospital. However, as previously noted, the observed prevalence of weakness was similar in the community dwelling British patients, many of whom had already received pulmonary rehabilitation. Prospective data from community dwelling COPD patients in the community not previously known to hospital physicians is required in order to estimate the prevalence of quadriceps weakness in both primary and hospital care.

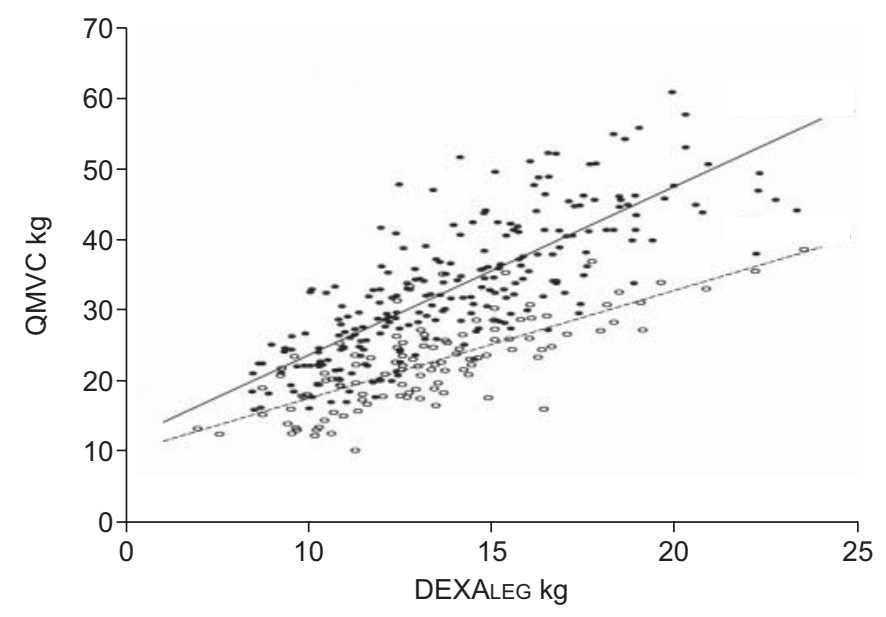

FIGURE 4. Relationship between regional lower limb lean mass measured by dual energy x-ray absorbtiometry (DEXALEG) and quadriceps maximum voluntary contraction strength (QMVC) in the Dutch chronic obstructive pulmonary disease cohort. Normal $(\bullet,-)$ and weak $(\bigcirc,----)$ quadriceps strength are shown: regression lines for each group are superimposed.

\section{Significance of the findings}

The prevalence of weakness in the absence of a severely reduced FEV1 warrants discussion, as does the observation that prior smoking history may be associated with quadriceps weakness in apparently healthy subjects without dyspnoea or airflow obstruction. Since reduced physical activity in general leads to muscle atrophy we suggest that some COPD patients may adopt a state of reduced activity before the onset of significant airflow obstruction or symptoms. This proposition is supported by the data of WATz et al. [33] who, using objective activity monitoring, demonstrated that only $26 \%$ of their cohort classified as GOLD stage 1 had a physical activity level considered "active" among healthy subjects. Evidence that patients fail to adopt a high-activity lifestyle for behavioural reasons may be inferred by a recent study reporting increased physical activity levels with prolonged rehabilitation, without further gains in quadriceps strength (the latter typically achieved over a shorter time frame) [34].

The second hypothesis is that cigarette smoking itself causes skeletal muscle disease, which, in turn, causes reduced physical activity. A direct effect of cigarette smoke has been suggested by studies that demonstrate increased quadriceps fatigue in young smokers [35, 36]. Abnormalities have also been reported in muscle biopsies from the vastus lateralis of smokers without COPD [37]. Interestingly, we could not detect an additional effect of current smoking status on strength in COPD in the present study.

Most studies investigating quadriceps strength have focused on cohorts of symptomatic, moderate-to-severe COPD patients. Although, as expected we found that increasing airflow obstruction classified by GOLD stage was associated with a trend toward a higher prevalence of quadriceps weakness, the association was not strong. The MRC scale describes dyspnoea in relation to general activity levels and its relationship with quadriceps weakness would tend to support a model whereby inactivity secondary to dyspnoea leads to 
muscle dysfunction. The contribution of severe dyspnoea appeared more predictive of quadriceps weakness than the degree of airflow obstruction.

Importantly, a low FFM index did not identify subjects at risk of quadriceps weakness, and comparable levels of BMI or FFM index were observed in COPD patients with or without weakness. A consensus on what constitutes a low FFM index in middle-aged and elderly populations, and the significance of any differences between countries has yet to be established. Others have reported that the prevalence of lower limb muscle wasting exceeds that of whole body lean mass depletion [26, 38]. The observation that quadriceps weakness in COPD occurs in the absence of FFM wasting suggests that such patients may benefit more from direct quadriceps intervention, such as pulmonary rehabilitation or neuromuscular electrical stimulation, than from systemic anabolic therapies.

Whilst maximal muscle strength is commonly considered a function of available muscle mass, the Dutch cohort provided evidence that phenotypical quadriceps weakness is more complex then simple atrophy alone. QMVC normalised for lower-limb lean mass (DEXALEG) was reduced in weak subjects, suggesting that both quality, as well as quantity of muscle may be altered. A similar finding for TwQ normalised for DEXALEG suggests that quadriceps weakness is not merely a deficit of voluntary muscle activation. This finding is at variance with smaller studies reporting a close relationship between muscle bulk and strength [17, 39], but is perhaps unsurprising given the larger sample reported. In one of these studies, QMVC normalised for mid-thigh cross-sectional area measured by computed tomography was reduced in subjects taking oral corticosteroids [39]. No effect of oral steroids was observed in the Dutch cohort, or indeed in a previous study reported by our group [40].

Given that quadriceps strength can convey prognostic information in COPD, and is not always a direct surrogate of low BMI or vice versa, QMVC may improve the prognostic power of indices such as the BODE score. In its original description, the BODE score was associated with a generalised $r^{2}$ of only 0.21 for predicting death in COPD. One-fifth of COPD patients in the BODE quartile associated with the best prognosis demonstrated quadriceps weakness; it is unknown if such patients may be at additional risk.

Reduced quadriceps strength relates to increased mortality and reduced exercise capacity in COPD. Overt and undetected disease represents a major public health challenge. This retrospective study demonstrates that quadriceps weakness is detectable in early disease as judged by predicted FEV1 or the MRC dyspnoea scale. Future studies of quadriceps function in community dwelling patients unknown to hospital services, and in apparently healthy ex-smokers, are needed to determine how widely this observation can be generalised beyond secondary care. Detection of weakness could in theory be achieved alongside spirometry screening programmes. Pulmonary rehabilitation can ameliorate skeletal muscle strength in COPD but has conventionally been reserved for symptomatic patients (MRC scores of $\geqslant 3$ ) [12]. It seems likely that patients with quadriceps weakness but only mild airflow obstruction may benefit from exercise-based training; although determining the optimal mode of delivery of such training to patients who may still be working or caring for family members may require innovative methodology.

In summary, we have derived a predictive equation for quadriceps strength from healthy subjects, that is suitable as a reference guide for patients with COPD, By applying this equation to two separate cohorts of COPD patients, we showed that approximately one-quarter of patients with mild COPD had quadriceps weakness. We suggest that inactivity and quadriceps strength may be an early feature of COPD in some patients, and may be amenable to rehabilitation.

\section{SUPPORT STATEMENT}

J.M. Seymour was funded by the British Lung Foundation, and an unrestricted educational grant from GlaxoSmithKline administered by the Royal Brompton Hospital, London, UK. N.S. Hopkinson was funded by the Wellcome Trust UK and the ENIGMA in COPD Project (European Union). S.A. Natanek was funded by the Wellcome Trust UK and an unrestricted educational grant from GlaxoSmithKline. W.D-C. Man was funded by the National Institute for Health (UK) Research Clinician Scientist Programme. A. Jackson was funded by the Moulton Foundation. Part of this project was undertaken at the NIHR Biomedical Research Unit in Advanced Lung Disease at the Royal Brompton and Harefield NHS Foundation Trust and Imperial College London. M.I. Polkey's salary was part-funded by the NIHR Biomedical Research Unit funding scheme. The views expressed in this publication are those of the authors and not necessarily those of the NHS, The National Institute for Health Research or the Department of Health.

\section{STATEMENT OF INTEREST}

Statements of interest for J.M. Seymour, S.A. Natanek and M.I. Polkey can be found at www.erj.ersjournals.com $/ \mathrm{misc} /$ statements.dtl

\section{ACKNOWLEDGEMENTS}

The authors wish to thank J. Peeters and L.O. het Veld (both Ciro, Centre of Expertise for Chronic Organ Failure, Horn, the Netherlands) for their assistance in collecting the Dutch cohort data.

\section{REFERENCES}

1 Skeletal muscle dysfunction in chronic obstructive pulmonary disease. A statement of the American Thoracic Society and European Respiratory Society. Am J Respir Crit Care Med 1999; 159: S1-S40.

2 Gosselink R, Troosters T, Decramer M. Peripheral muscle weakness contributes to exercise limitation in COPD. Am J Respir Crit Care Med 1996; 153: 976-980.

3 Decramer M, Gosselink R, Troosters T, et al. Muscle weakness is related to utilization of health care resources in COPD patients. Eur Respir J 1997; 10: 417-423.

4 Swallow EB, Reyes D, Hopkinson NS, et al. Quadriceps strength predicts mortality in patients with moderate to severe chronic obstructive pulmonary disease. Thorax 2007; 62: 115-120.

5 Man WD, Soliman MG, Nikoletou D, et al. Non-volitional assessment of skeletal muscle strength in patients with chronic obstructive pulmonary disease. Thorax 2003; 58: 665-669.

6 Gea JG, Pasto M, Carmona MA, et al. Metabolic characteristics of the deltoid muscle in patients with chronic obstructive pulmonary disease. Eur Respir J 2001; 17: 939-945.

7 Polkey MI, Moxham J. Attacking the disease spiral in chronic obstructive pulmonary disease. Clin Med 2006; 6: 190-196.

8 Fletcher CM, Elmes PC, Fairbairn AS, et al. The significance of respiratory symptoms and the diagnosis of chronic bronchitis in a working population. Br Med J 1959; 2: 257-266. 
9 Spruit MA, Pennings HJ, Janssen PP, et al. Extra-pulmonary features in COPD patients entering rehabilitation after stratification for MRC dyspnea grade. Respir Med 2007; 101: 2454-2463.

10 Simpson K, Killian K, McCartney N, et al. Randomised controlled trial of weightlifting exercise in patients with chronic airflow limitation. Thorax 1992; 47: 70-75.

11 Pulmonary rehabilitation survey: The British Thoracic Society and British Lung Foundation, 2003.

12 NICE. Chronic obstructive pulmonary disease: National clinical guideline for management of chronic obstructive pulmonary disease in adults in primary and secondary care. Thorax 2004; 59: Suppl. I.

13 Swallow EB, Reyes D, Hopkinson NS, et al. Quadriceps strength predicts mortality in patients with moderate to severe chronic obstructive pulmonary disease. Thorax 2007; 62: 115-120.

14 Edwards RH, Young A, Hosking GP, et al. Human skeletal muscle function: Description of tests and normal values. Clin Sci Mol Med 1977; 52: 283-290.

15 Decramer M, Lacquet LM, Fagard R, et al. Corticosteroids contribute to muscle weakness in chronic airflow obstruction. Am J Respir Crit Care Med 1994; 150: 11-16.

16 Hopkinson NS, Nickol AH, Payne J, et al. Angiotensin converting enzyme genotype and strength in chronic obstructive pulmonary disease. Am J Respir Crit Care Med 2004; 170: 395-399.

17 Seymour JM, Ward K, Sidhu PS, et al. Ultrasound measurement of rectus femoris cross-sectional area and the relationship with quadriceps strength in COPD. Thorax 2009; 64: 418-423.

18 Swallow EB, Barreiro E, Gosker H, et al. Quadriceps muscle strength in scoliosis. Eur Respir J 2009; 34: 1429-1435.

19 Rabe KF, Hurd S, Anzueto A, et al. Global strategy for the diagnosis, management, and prevention of chronic obstructive pulmonary disease: GOLD executive summary. Am J Respir Crit Care Med 2007; 176: 532-555.

20 Celli BR, Cote CG, Marin JM, et al. The body-mass index, airflow obstruction, dyspnea, and exercise capacity index in chronic obstructive pulmonary disease. N Engl J Med 2004; 350: 1005-1012.

21 Swallow EB, Gosker HR, Ward KA, et al. A novel technique for nonvolitional assessment of quadriceps muscle endurance in humans. J Appl Physiol 2007; 103: 739-746.

22 Steiner MC, Barton RL, Singh SJ, et al. Bedside methods versus dual energy x-ray absorptiometry for body composition measurement in COPD. Eur Respir J 2002; 19: 626-631.

23 Miller MR, Hankinson J, Brusasco V, et al. Standardisation of spirometry. Eur Respir J 2005; 26: 319-338.

24 Macintyre N, Crapo RO, Viegi G, et al. Standardisation of the single-breath determination of carbon monoxide uptake in the lung. Eur Respir J 2005; 26: 720-735.
25 Wanger J, Clausen JL, Coates A, et al. Standardisation of the measurement of lung volumes. Eur Respir J 2005; 26: 511-522.

26 Engelen MP, Schols AM, Does JD, et al. Skeletal muscle weakness is associated with wasting of extremity fat-free mass but not with airflow obstruction in patients with chronic obstructive pulmonary disease. Am J Clin Nutr 2000; 71: 733-738.

27 Polkey MI, Kyroussis D, Hamnegard CH, et al. Quadriceps strength and fatigue assessed by magnetic stimulation of the femoral nerve in man. Muscle Nerve 1996; 19: 549-555.

28 ATS statement: Guidelines for the six-minute walk test. Am J Respir Crit Care Med 2002; 166: 111-117.

29 Mador MJ, Bozkanat E, Kufel TJ. Quadriceps fatigue after cycle exercise in patients with COPD compared with healthy control subjects. Chest 2003; 123: 1104-1111.

30 Jones PW, Quirk FH, Baveystock CM, et al. A self-complete measure of health status for chronic airflow limitation. The St. George's Respiratory Questionnaire. Am Rev Respir Dis 1992; 145: 1321-1327.

31 Vestbo J, Prescott E, Almdal T, et al. Body mass, fat-free body mass, and prognosis in patients with chronic obstructive pulmonary disease from a random population sample: Findings from the copenhagen city heart study. Am J Respir Crit Care Med 2006; 173: 79-83.

32 Schols A, Soeters PB, Dingemans AM, et al. Prevalence and characteristics of nutritional depletion in patients with stable copd eligible for pulmonary rehabilitation. Am Rev Respir Dis 1993;147: $1151-1156$.

33 Watz H, Waschki B, Boehme C, et al. Extrapulmonary effects of chronic obstructive pulmonary disease on physical activity: A cross-sectional study. Am J Respir Crit Care Med 2008; 177: 743-751.

34 Pitta F, Troosters T, Probst VS, et al. Are patients with copd more active after pulmonary rehabilitation? Chest 2008; 134: 273-280.

35 Morse CI, Wust RC, Jones DA, et al. Muscle fatigue resistance during stimulated contractions is reduced in young male smokers. Acta Physiol (Oxf) 2007; 191: 123-129.

36 Wust RC, Morse CI, de Haan A, et al. Skeletal muscle properties and fatigue resistance in relation to smoking history. Eur J Appl Physiol 2008; 104: 103-110.

37 Montes de Oca M, Loeb E, Torres SH, et al. Peripheral muscle alterations in non-COPD smokers. Chest 2008; 133: 13-18.

38 Hopkinson NS, Tennant RC, Dayer MJ, et al. A prospective study of decline in fat free mass and skeletal muscle strength in chronic obstructive pulmonary disease. Respir Res 2007; 8: 25.

39 Bernard S, LeBlanc P, Whittom F, et al. Peripheral muscle weakness in patients with chronic obstructive pulmonary disease. Am J Respir Crit Care Med 1998; 158: 629-634.

40 Hopkinson NS, Man WD, Dayer MJ, et al. Acute effect of oral steroids on muscle function in chronic obstructive pulmonary disease. Eur Respir J 2004; 24: 137-142. 